ISSN 1112-9867

http://www.jfas.info

\title{
AN ARCHITECTURE OF MULTIAGENT SYSTEM (MAS) FOR HEALTHCARE INTELLIGENT DECISION SUPPORT SYSTEM (IDSS)
}

\author{
N. Mahiddin*, Z. A. Othman and A. A. Bakar \\ Faculty of Information Science and Technology, National University of Malaysia, 43600 \\ Bangi, Selangor, Malaysia
}

Published online: 17 October 2017

\begin{abstract}
Healthcare decision making is complex. It involves many collecting information which keeps changing in certain time. Then, current healthcare decision making process is based on stages in the healthcare delivery system (subsystem in healthcare). The accurate decision-making in healthcare suppose is not solely on the end of a particular stage of the healthcare delivery system, but it should be done at each stage. Moreover, decision making at each stage also sometimes happens concurrently. Consequently, this paper focus on the healthcare workflow and proposed a CARE concept with MAS technology to be as a solution for the problems identified.
\end{abstract}

Keywords: Decision Support System (DSS); Healthcare; Intelligent Decision Support System (IDSS); Multiagents System (MAS).

Author Correspondence, e-mail: normadiah@gmail.com

doi: http://dx.doi.org/10.4314/jfas.v9i5s.12 


\section{INTRODUCTION}

Health is a priceless gift and it is indeed a dream of everyone. Thus, the healthcare emerges to ensure a good health throughout the time. Healthcare is a system (management context) which consist elements (interrelated), boundaries and stages. The healthcare system can be divided into two categories which are healthcare provider's management or administration and clinical practice [1]. Hence, in this research, we are only focusing on clinical practice. The healthcare delivery system is a subsystem of the healthcare system itself that refer to the stage of healthcare services deliver for patients [2]. In general, there are five stages of the healthcare delivery system which are primary care, secondary care, tertiary care, quaternary care and palliative care [3]. The detail about these five stages of healthcare was described previously. The primary care is a basic healthcare services deliver to people in a community [4]. Then, secondary care is a healthcare services deliver to patients which consist the activities focused on early disease detection to prevent progression of the disease [3]. Next, tertiary care is a healthcare services deliver to patients, which consist the treatments to reduce the impact of an already established disease by reducing disease related complications [3]. Afterward, quaternary care is a healthcare services deliver to patients which consist the treatments experimental medicine and procedures, and highly uncommon, specialized surgeries [5]. Finally, palliative care is a healthcare services deliver to patients, which consist a specialized care focused on the management of physical, psychosocial and spiritual needs of patients and families experiencing serious illness [6].

The target of healthcare is to have the right and accurate diagnosis, treatment and prevention of specific health condition [7]. The quality and effectiveness of healthcare highly depend on healthcare services delivered by healthcare practitioners in a particular healthcare provider. Thus, in order to achieve the best healthcare services, decision making plays a main role in healthcare services. This is closely related to the decision made by the authorized healthcare practitioners or the decision makers in the healthcare field. Consequently, in [8] suggested a healthcare decision making process framework to clarify those healthcare decision making processes. Meanwhile, in [9] came out with the concept of guidelines, clinical pathways and decision nodes in clinical decision support system (CDSS). The decision nodes concepts 
shows the decisions in healthcare are interrelated between each other. This is due to the process of decision-making in healthcare which also depends on certain variables, which relate to the other variables. An example, a medical data on patient's blood pressure is related to the patient's age. A different category of age has a different level of normal blood pressure. These situations where many parameters need to be taken into consideration in healthcare decision making, made the healthcare workflow become complicated and become one of the main factors of complexity in healthcare decision making.

The complexity in healthcare decision making also involved many collecting information, especially from medical devices such as x-ray, blood test and many others. All these and many other clinical information keep changing and keep growing through time until becoming a huge amount of data. These situations definitely will influence the accuracy of healthcare decision making. As a consequence, healthcarewas maintained as one of an active area in DSS research recently. The existing DSS researches proved that DSS really improved the healthcare services at each healthcare delivery system as shown in Table 1. Currently, DSS development also showed a wide use of data mining technique. This is because the efficacy of using the data mining approach or known as intelligent technique in the DSS development. The use of data mining technique in DSS had known the system as Intelligent Decision Support System (IDSS). Presently, the IDSS research in healthcarewas growing rapidly due to the information avalanche of health data. This situation made healthcare sector become more complex than it was at previous [10].

Next, generally, decision making happens in each healthcare delivery system. However, current healthcare decision making process is based on stages in the healthcare delivery system as shown in Table 2 . Hence, the probability of not getting correct, accurate and timely decision is very high. The accurate decision-making in healthcare suppose is not solely on the end of a particular stage of the healthcare delivery system, but it should be done at each stage. This is because every decision made in healthcare relates to the decisions made previously. An example, a decision made in primary care stages will influence decisions in secondary care. Meanwhile, a decision made in secondary care also will influence decisions in tertiary care and so on. Hence, in this paper, we showed the scenario of the healthcare system and focus 
into decisions relating in the healthcare workflow. As a result, we propose the CARE concept to simplify the healthcare workflow in the healthcare decision-making process.

Furthermore, currently, most of the healthcare delivery system were in distributed places based on healthcare providers. Moreover, the healthcare decision making at each stage of the healthcare delivery system also sometimes happens concurrently. Therefore, decision making in healthcare is crucial. These situations showed a need to update patient's medical data in every stage of the healthcare delivery system. Therefore, a multiagent system (MAS) technology is an appropriate solution to overcome these problems. The MAS is a powerful platform in computing technology that comprised of multiple intelligent agents interacting each other's. Meanwhile, intelligent agents are software which has capabilities of flexible autonomous action to meet its design objectives and interacting among them [11]. MAS has been identified as a powerful technology to solve a real world problem such as healthcare sectors. This is because the MAS have the capabilities of; 1) provide a simplification in modelling complex problems, especially like healthcare sector [12], 2) distributed and concurrent system [13], 3) divide and conquer concept that facilitates scalability and reutilization [11] and 4) has the ability to solve a privacy issue of data sharing in the healthcare sector [14]. Therefore, in this paper, we presented an initial architecture of MAS for healthcare IDSS that allows the decision maker in the healthcare delivery system to look and investigate in the whole context in healthcare stages of treatment.

\section{RELATED WORK}

\subsection{DSS in Healthcare}

The existing research in DSS showed healthcare is one of an active area in DSS research. In general, DSS research in healthcare can be divided into two categories; (1) healthcare providers' management or administration, and (2) clinical practice [1]. In this research, we are focusing in the healthcare decision making process in the category of clinical practice. This is because the clinical workflow in healthcare is complex and very complicated. The failure to identify an unexpected workflow in healthcare will contribute to the risk factors of make errors in advising or in diagnoses [15]. Therefore, this research is focused into the problem of 
identifying clinical workflow in healthcare.

The DSS in clinical practice is named as Computer-Based Medical Decision Support System (CBMDSS) or Clinical Decision Support System (CDSS) [10]. The healthcare practitioners play important role in the process of decision making in healthcare, however, there are many reasons like misunderstanding, unfamiliarity with related processes and disinterest make the participation become inconsistent and sometimes be an obstacle. Therefore, in [8] came out with the healthcare decision making process framework to clarify those processes including the healthcare practitioner's role. The process steps in the healthcare decision-making process framework were as follows; (1) Identify situations where healthcare decision making is needed, (2) Identify and clarify existing care instructions, (3) Clarify medical issues, (4) Define decision-making capacity, (4) Identify the primary decision maker, (5) Certify the existence of any qualifying conditions, (6) Define and present relevant healthcare issues, (7). Implement choices related to healthcare decisions, (8) Review the situation and continue or modify approaches as appropriate $[1,15]$. This showed the importance to identify the clinical workflow based on healthcare nature for the purpose of healthcare decision-making process. Thus, many efforts had done in DSS research to improve the healthcare delivery system. Table 1 showed the results of existing research on the use of DSS in healthcare. It showed the use of DSS had improved the healthcare delivery system for people. Hence, in [9] had come with the concept of guidelines, clinical pathways and decision nodes in clinical decision support system (CDSS). A guideline is defined as a methodically developed set of recommendations concerning a specific health problem which serves as a helpful tool in the decision making process. 
Table 1. Researches on the use of DSS in healthcare

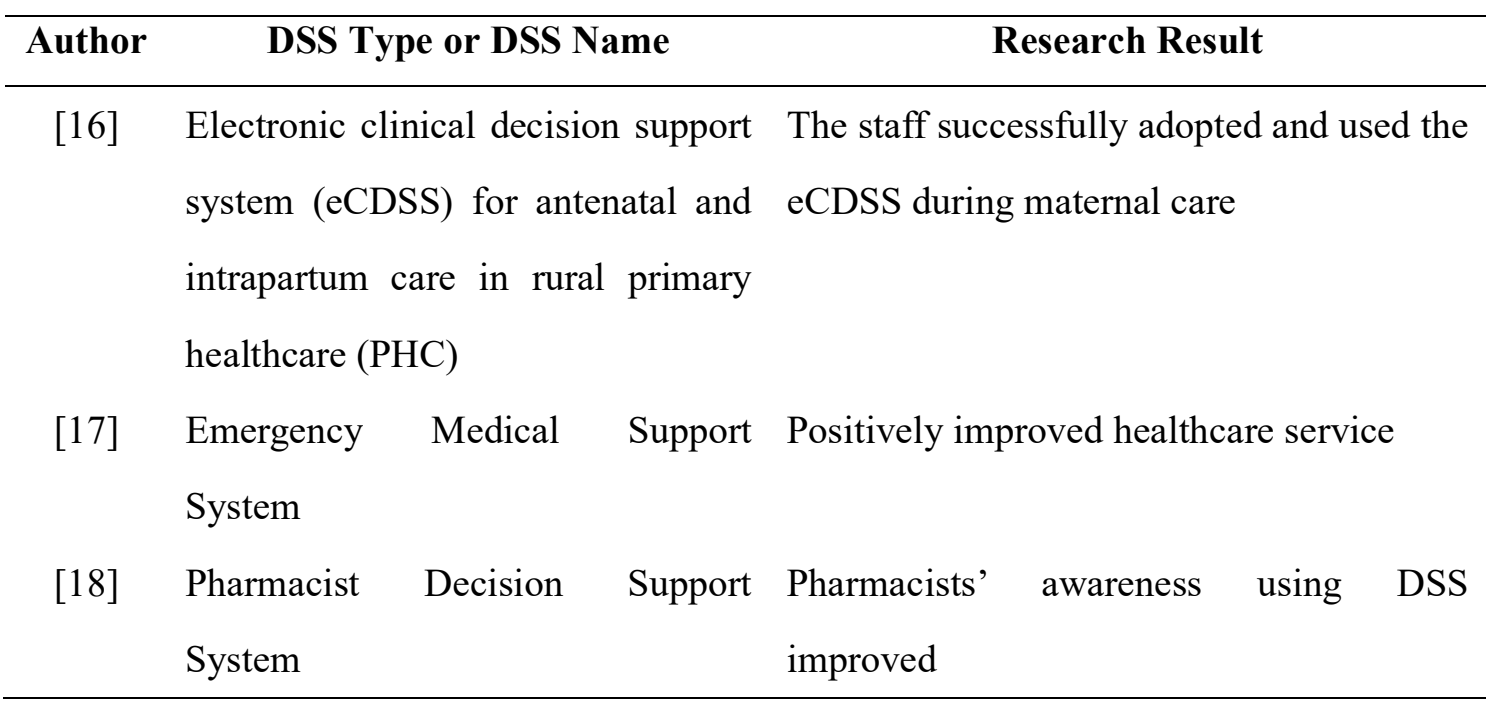

Then, clinical pathways or other name is care paths is defined as the systems of interrelated actions, represented in a particular notation and providing support for healthcare practitioners during diagnostic work-up, determination of the nature, course of treatment, leading to the improved quality and effectiveness of medical services. Meanwhile, decision nodes are defined as a sequence of tasks and actions [10]. Fig.1 shows the example on the use of decision nodes as proposed by [9]. This shows the decisions in healthcare are interrelated between each other. This also showed the importance to identify the healthcare workflow based on healthcare nature for the purpose of healthcare decision-making process.

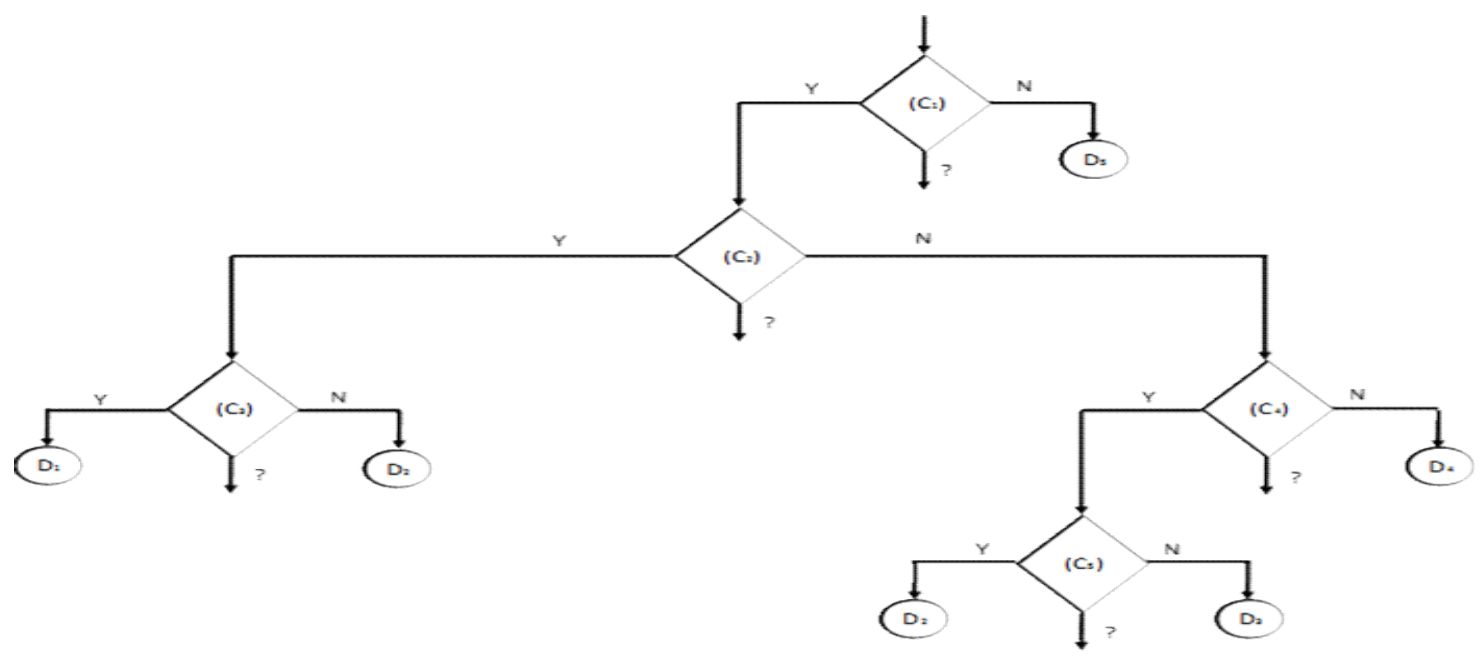

Fig.1. Component decision nodes of the $\mathrm{C}$ node

Next, Table 2 showed the existing DSS research in healthcare. All of the existing DSS in Table 2 were developed and focused only in one stage of the healthcare delivery system. 
An example; (1) in [19] was developing the DSS only in tertiary care use, (2) in [20] was developing the DSS also only in tertiary care use, (3) in [21] was developing the DSS only in secondary care use and many more as such as shown in Table 2 . These means current decision making in healthcare is diagnosed based on a particular stage (primary care, secondary care, tertiary care or etc.). Thus, a decision making is not based on the whole context in a healthcare stage of treatment. Therefore, the probability of not getting a correct, accurate and timely decision is very high. As a consequence, we need a DSS, which allow the decision maker to look and investigate in the whole context in a healthcare stage of treatment. Therefore, we are focusing into the problem in finding the accurate decision workflow in healthcare that will influence the accuracy in healthcare decision making.

Hence, data mining techniques had used widely in DSS development since the previous until currently. This is because data mining is a process of discovering interesting patterns and knowledge from large amounts of data [22]. Through data mining, we can turn a large collection of data into knowledge. Henceforth, most of existing DSS researches in healthcare showed the efficacy of using data mining approach in the DSS development for healthcare sectors. Consequently, we found data mining is a compulsory feature in solving complex environment like healthcare domain.

Table 2. DSS in healthcare

\begin{tabular}{cccc}
\hline Author & Specific Purpose & Stageof Care & Aspect of Contribution \\
\hline$[19]$ & Radiation oncology & Tertiary care & $\begin{array}{c}\text { Shared Decision Making } \\
\text { (Personalized and Participative) }\end{array}$ \\
{$[20]$} & Childhood cancer & Tertiary care & Technique to design CDSS-think aloud \\
& survival & & method and propositional analysis \\
{$[23]$} & Operating Room & Tertiary care & DSS development with embeds \\
& scheduling & & optimization procedures \\
{$[24]$} & Chronic & Tertiary care & Present clinical pathway in a healthcare \\
& Obstructive & & workflow \\
& Pulmonary Disease & & Data model
\end{tabular}


medicine

[25]

$\begin{array}{cc}\text { Pathology Ordering } & \text { Secondary care } \\ \text { Cardiovascular } & \text { Tertiary care } \\ \text { Risk Level } & \\ \text { Prediction } & \end{array}$

Psychological Secondary care

Diagnosis

$\begin{array}{cc}\text { Telerehabilitation } & \text { Palliative care } \\ \text { Dental Restoration } & \text { Secondary care } \\ \text { Care for } & \text { Tertiary care }\end{array}$

Chronically ill

Patients

$$
\text { Radiotherapy Tertiary care }
$$

Treatment Planning

Risk assessment of

Cardiac Chest Pain

Nutrition diagnosis

Polysomnography

Diagnosis and

Monitoring of

Multiple Sclerosis

Diagnosis Related

Groups Coding

Informational

Support

$\begin{array}{cc}\text { Psychiatry Problem } & \text { Secondary Care } \\ \text { Diagnosis of } & \text { Secondary Care } \\ \text { Malaria } & \end{array}$

Hybrid Technique

Hybrid Technique

Ontology

Ontology

Ontology

Ontology

Hybrid Technique

Hybrid Technique

Hybrid Technique

Hybrid Technique

Ontology

Hybrid Technique

Agent

Hybrid Technique

Hybrid Technique 


\subsection{Multiagent Systems in Healthcare}

There are various researches have been done in applying MAS in healthcare. Table 3 showed some of the existing researchprojects related tomultiagent systems in healthcare. Based on Table 3, the existing researches showed the MAS have been applied for multiple purposes of the research project in healthcare. Most of the research project involved in distributed system. In [44] developed Virtual Electronic Patient Record (VEPR) system to provide the updated patient medical history at all points of care. In general, the VEPR has been developed for data retrieval and integration using the JADE framework as a multiagent system platform [7].

Meanwhile, in [45] developed Context-aware Hospital Information System (CHIS) to provide privacy aware application in pervasive computing environments [7]. Then, in [40] developed Healthagents to support information extraction and analysis in a timely fashion for diagnosis and prognosis of black tumors. Hence, in [41] developed Multi-Agent Distributed information Platform (MADIP) on Java Agent Development (JADE) Framework to notify the responsible care-provider of abnormality automatically. Then, in [13] developed a MAS for medical diagnosis using a blackboard control approach based on medical specialist character as an agent.

Further, in [42]developed U-healthcare agent system based on the convergence model for ubiquitous networking and environment. The convergence model here means the combination methodology used between the distributed mobile agents with the medical entities. Next, in [43] developed a MAS based DSS for management of the Pediatric Emergency Department. This MAS based DSS was developed using the JADE framework and focused into preventing from overcrowding features in healthcare. Subsequent, in [47] developed a collaborative software agent framework for information exchange within the medical diagnosis process. The intelligent agents developed based on human body systems such as respiratory and cardiovascular.

Finally, the MAPP4MD was developed to address the problem on maintenance of confidentiality of personal medical data in data sharing. The MAPP4MD system had taken into account the need of data sharing for knowledge discovery for evidence based medicine (EBM). The MAPP4MPD system consists of three types of agents. The types of agents were 
differentiated based on three interacting layers of tiers which are called local healthcareorganization'sagent (LHOA), broker agent and repository agent. The LHOA was assigned to meet the unique requirements of each healthcare organization and deployed to its respective organization site.

Meanwhile, the broker agent was assigned for communications between all agents. Then, repository agent was assigned to transfer data to a clinical data warehouse for knowledge discovery. This type of communication is an ordinary communication in distributed systems. Furthermore, the MAPP4MPD system was only focused only on data and didn't bother on the healthcare workflow in healthcare decision making [14].

Thus, in [46] only proposed a model for agent-based hospital information system based on the utilization of agent characteristics. Overall, none of the research project showed in Table 3 looking at the whole context of healthcare decisions making workflow in the healthcare nature. Healthcare is a complex field that involve distributed environment, has a dynamic data that keep changing, face situation where decision making sometime happen concurrently and sometime autonomous. Therefore, this research is focusing on modeling a system that can look and investigate in the whole context of healthcare decisions making workflow in the healthcare nature. This is because, the feature of allowing the system to look and investigate in the whole context in healthcare is very important, in order to produce a high quality and accuracy of healthcare decision making.

Table 3.Multiagentsystems in healthcare

\begin{tabular}{ccccc}
\hline Author & $\begin{array}{c}\text { Name of MAS } \\
\text { in Healthcare }\end{array}$ & $\begin{array}{c}\text { Design-Model of } \\
\text { the System }\end{array}$ & $\begin{array}{c}\text { System } \\
\text { Implementation }\end{array}$ & Research Focus \\
\hline Virtual & Consist MAS for & Implemented in & Data retrieval \\
[44] & Electronic & Integration of Data & JAVA using the & and its \\
Patient Record & (MAID) module, & JADE Framework & integration \\
(VEPR) & $\begin{array}{c}\text { visualization module } \\
\end{array}$ & (VIZ) and CRep & & \\
& & &
\end{tabular}


[45]

$\begin{array}{cccc}\text { Context-aware } & \text { Privacy aware } & \text { Implement } & \text { Pervasive } \\ \text { Hospital } & \text { application } & \text { multiagent pervasive } & \text { computing } \\ \text { Information } & & \text { system } & \end{array}$

System

(CHIS).

[40] Health Agents.

Based on
Healthagentsmulti-
layer framework.
Based on human
agent in the real
world
scenario-physician
agent, user agent,
diagnostic agent.

DSS comprised of an agent-based architecture with an associated ontology, data mining techniques and the protocols for clinical data exchange.

[41]

$\begin{array}{cc}\begin{array}{c}\text { Multi-Agent } \\ \text { Distributed }\end{array} & \begin{array}{c}\text { Based on human } \\ \text { information }\end{array} \\ \text { Platform } & \text { world } \\ \text { (MADIP) } & \text { agent, user agent, } \\ & \text { diagnostic agent. }\end{array}$

Agent-based DSS

$\begin{array}{cc}\begin{array}{c}\text { Implemented in } \\ \text { JAVA using the }\end{array} & \begin{array}{c}\text { A highly } \\ \text { distributed }\end{array} \\ \text { JADE Framework. } & \text { information } \\ \text { infrastructure to } \\ \text { notify the } \\ \text { responsible } \\ \text { care-provider of } \\ \text { abnormality } \\ \text { automatically. }\end{array}$

[46]

\begin{tabular}{|c|c|c|c|}
\hline Multi-agent & Proposed model for & Not implement yet. & Providing \\
\hline System for & agent-based hospital & & agent-based \\
\hline E-health & information system. & & system for the \\
\hline \multirow[t]{4}{*}{ Functionalities } & & & hospital by the \\
\hline & & & utilization of \\
\hline & & & agent \\
\hline & & & characteristics. \\
\hline
\end{tabular}




\section{METHODOLOGY}

In this research, we performed eight steps of research methodologies as shown in Fig. 2 to identify the best solution for the problem we identified. Based on Fig. 2, the eight steps we applied were literature review that consist of an existing research article, review, together with books and document review. We organized a systematic literature review on some selected research papers, medical books and computer science book. We performed the literature review of research papers we selected initially with categorized the research papers into three categories which are healthcare nature, DSS inhealthcare and multi-agents technology. After that we find out the differentiation, the similarities, the aspects of methodology, the exemplary studies, the gaps in research, the relationship between current studies with previous studies, the drawbacks and etc. After that, we did documents review base on our selected case study. Here, we selected kidney disease as our case study. Therefore, we did review on the clinical practice guideline documents for kidney disease from Ministry of Health of Malaysia, dialysis patient's form from a particular hemodialysiscenter and a few samples of patient's blood test result. Then, discussion with healthcare practitioners involved interviews and discussion with medical and computer science experts.

As a result, we proposed a healthcare decision making workflow concept. Afterwards, the concept we proposed in this research was presented in front of a group of medical experts from Advanced Medical and Dental Institute (AMDI), UniversitiSains Malaysia, Kepala Batas, Penang. There are nine medical experts from various medical specializations involved in evaluating the project presentation. Next, after a minor correction had done on the concept proposed, it was validated by the group of medical experts from AMDI to be accepted to apply in the healthcare domain. Consequently, in this paper, we present a validated concept of healthcare decision making workflow. After that, we do knowledge discovery and implementation involved activities of generating medical data simulation based on medical expert information and data mining process. Finally, we proposed a MAS for healthcare IDSS as a complete solution. 


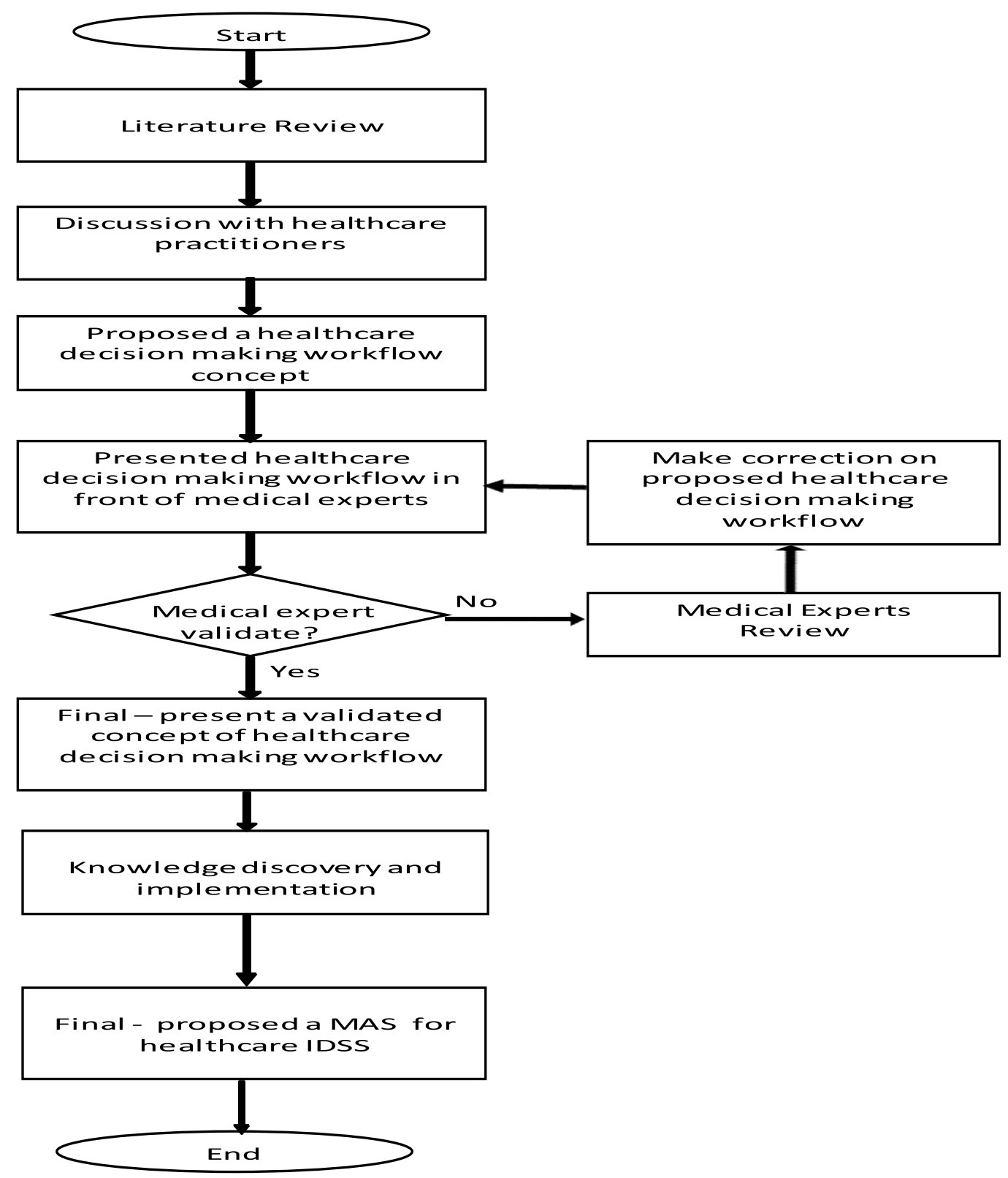

Fig.2. Research methodology

\section{SCENARIOS IN HEALTHCARE}

In order to see clearly, the reality in the current scenario of healthcare especially in Malaysia, an interview and discussion with healthcare practitioners have been done. As a result, Fig. 3 showed the illustration on the current scenario in healthcare in Malaysia. Based on Fig.3, there were only two basic functions that play main role in the current healthcare system in Malaysia. The two basic functions are inserting data and retrieve data. Once the decision 
maker's key in data in the health information system, the system will insert the data into a database. Once the decision maker request the patient information, the health information system will retrieve data from the database and the system will only display the information that kept in the database to the user. Thus, this traditional health information system is lack of efficiency to be applied in the healthcare domain. Currently, the healthcare domain is very complex with a growing of medical knowledge, a growing size of medical data, a dynamic data and process, a distributed environment and a concurring decision making by healthcare decision makers in different point of care.

Hence, based on our study, currently, there are five stages of care related tohealthcare as shown in Fig.4. They are primary care, secondary care, tertiary care, quaternary care and palliative care. The definitions of each level of care have been described previously. The primary care service is a basic care provided for people in a community. The primary care services are usually delivered by nurse practitioners, medical assistants, dieticians, mental health professionals, pharmacists, therapists or sometimes by a medical officer or specialist.

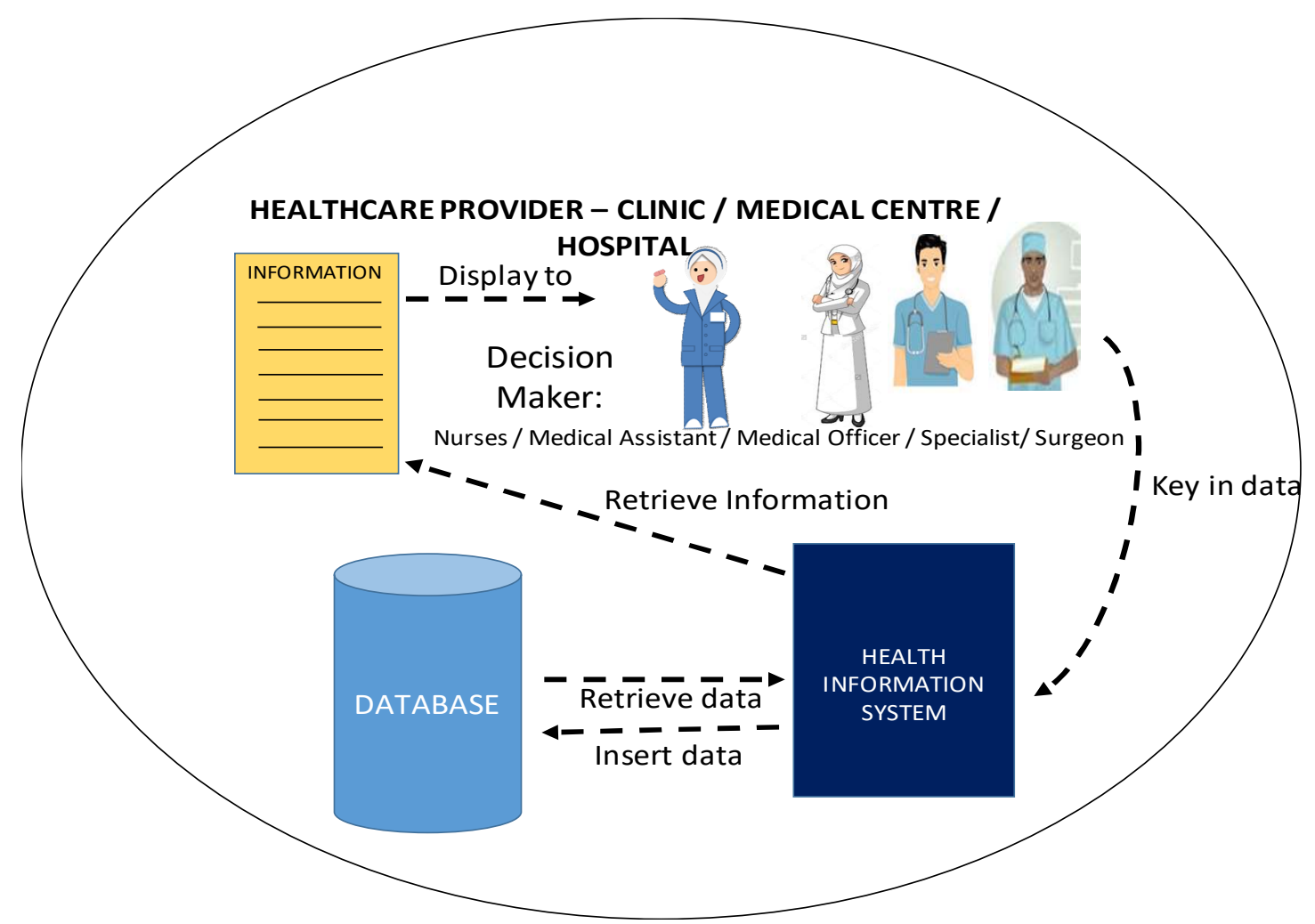

Fig.3.Current scenario of healthcare system in Malaysia 
The primary care services delivered in primary care also was included the prevention, diagnosis, treatment, follow-up of various health conditions and referrals to specialists in secondary care services. Hence, there are three decision makers involved in this stage that are medical assistant, medical officer and specialist. A decision decided as referral could be submitted to the next stage either secondary care or directly to palliative care. Further, the primary core stage also can receive a decision decided as continue follow up from the secondary care stage or palliative care stage.

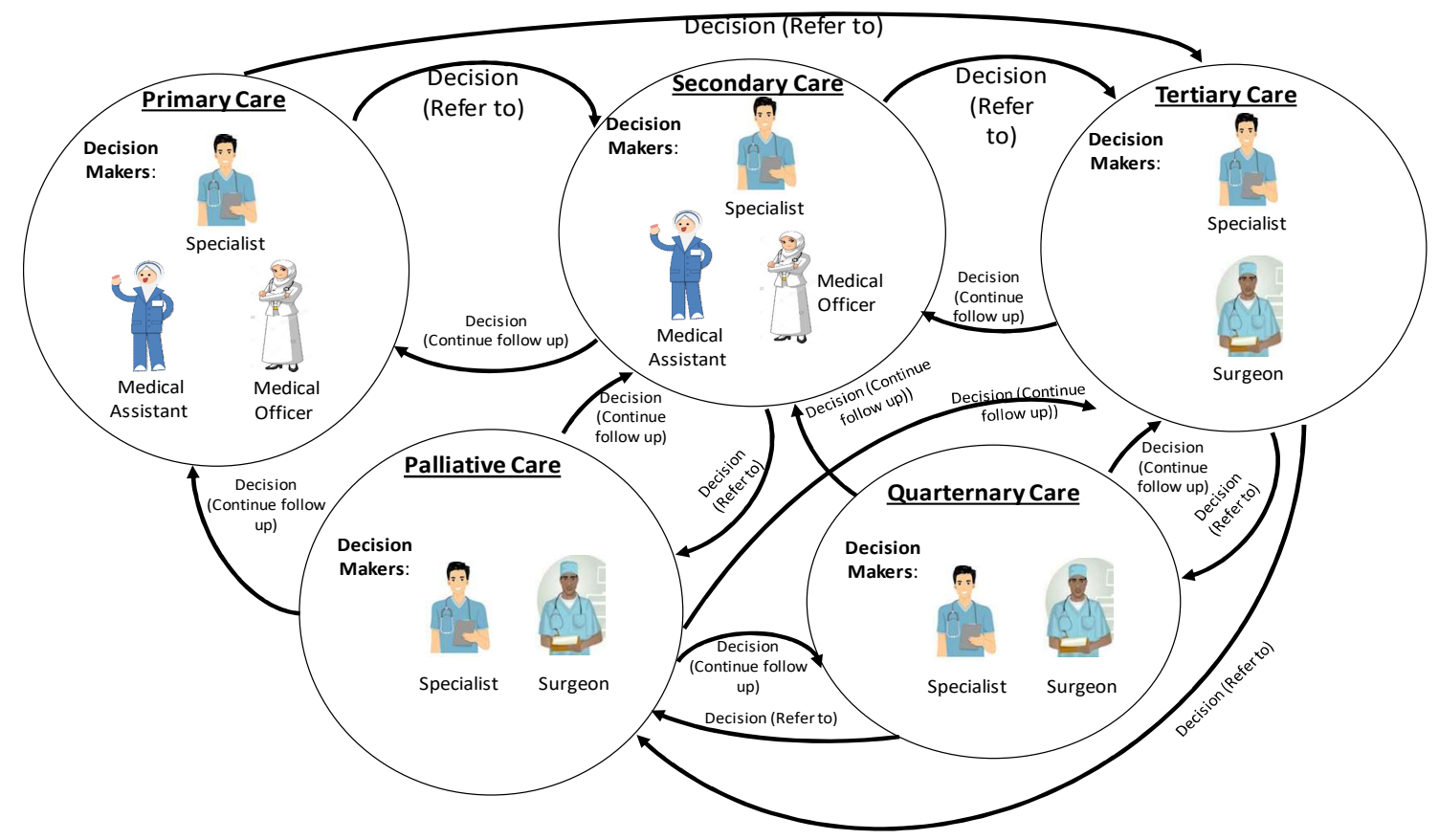

Fig.4.The scenery on the nature of decision making in healthcare based on the healthcare delivery system

Then, the following care is a secondary care. Secondary care is a care provided by a person who has more specific expertise called a specialist. Usually, secondary care involved more detail the diagnosis and treatment such as scan. Hence, the decision maker in secondary care are medical officer, specialist and surgeon. Henceforth, a decision decided as referral could be submitted to the next stage either tertiary care or directly to palliative care. Further, the secondary care stage also can receive a decision decided as continue follow up from the tertiary care stage, quaternary care stage or palliative care stage.

Afterward, tertiary care is another care which is a higher level care compare to secondary care. 
Tertiary care is a specialty care which needs highly specialized equipment and specialty. The tertiary care servicesare usually delivered within a hospital or medical center. An example of the tertiary care being delivered is such as a dialysis center for hemodialysis patient. Further, there are three decision makers involved in this stage that are medical officer, specialist, and a surgeon. A decision decided as referral could be submitted to the next stage either quaternary care stage or directly to palliative care. Further, the tertiary care stage also can receive a decision decided as continue follow up from quaternary care stage or palliative care stage. Hence, the extension of tertiary care is a quaternary care.

The quaternary care is a highly specialized care with a target to cure. The types of care is such as experimental medicine and procedures and specialized surgeries. An example treatment delivered in quaternary care services is such as transplant operation. Next, there are two decision makers involved in this stage that are specialist and surgeon. A decision decided as referral could be submitted to the next stage that is palliative care. Further, the quaternary care stage also can receive a decision decided as continue follow up from the palliative care stage. Finally, palliative care is a specialized care provided by various healthcare practitioners including social workers for people with severe illnesses. Traditionally in medical knowledge, palliative care is a care for people with serious illnesses which have been looking as hopeless in life by healthcare practitioners. However, the medical knowledge keeps growing as the time going on. Currently, palliative care has been looking as a care to help patient with illnesses to have longer survival with a better health condition compare to previous condition. Subsequently, there are two decision makers involved in this stage that are specialist and surgeon. Palliative care is a special stage of care comparable to the other stage of care because it's only submit a decision type of continue follow up and received a decision type of referral.

\section{DECISIONS WORKFLOW IN HEALTHCARE: A CARE CONCEPT}

Based on interview and discussion with healthcare practitioners and literature review, we present a concept of healthcare decision making as shown in Fig. 5. The concept was entitled as a CARE concept. This CARE concept had presented in front of a group of medical experts from various specializations at Advanced Medical and Dental Institute (AMDI) of 
UniversitiSains Malaysia. Afterward, this CARE concept had validated to be accepted for the purpose of this research.

Henceforth, refer to Fig. 5, all flows denoted with a, b, c, d, e, f, g, h, I, j, k, 1, m, n, o were represent decisions made by decision makers in each stage of healthcare delivery services. An example, $a$ is a decision made by Medical Assistant (MA) or Medical Officer (MO). Then, a decision will be passed to another Medical Officer working in secondary care stage. At the secondary care stage, a decision will influence the decision making of the decision maker at this stage. After that, the decision maker at secondary stage will make b decision that has better quality and accuracy since the decision making process had taken into account the previous decision. Then, this $\mathrm{b}$ decision will be passed to the next stage named tertiary care. Hence, the same flow as shown in Fig. 5 will be followed if necessary based on the patient's condition in a particular stage of healthcare service.

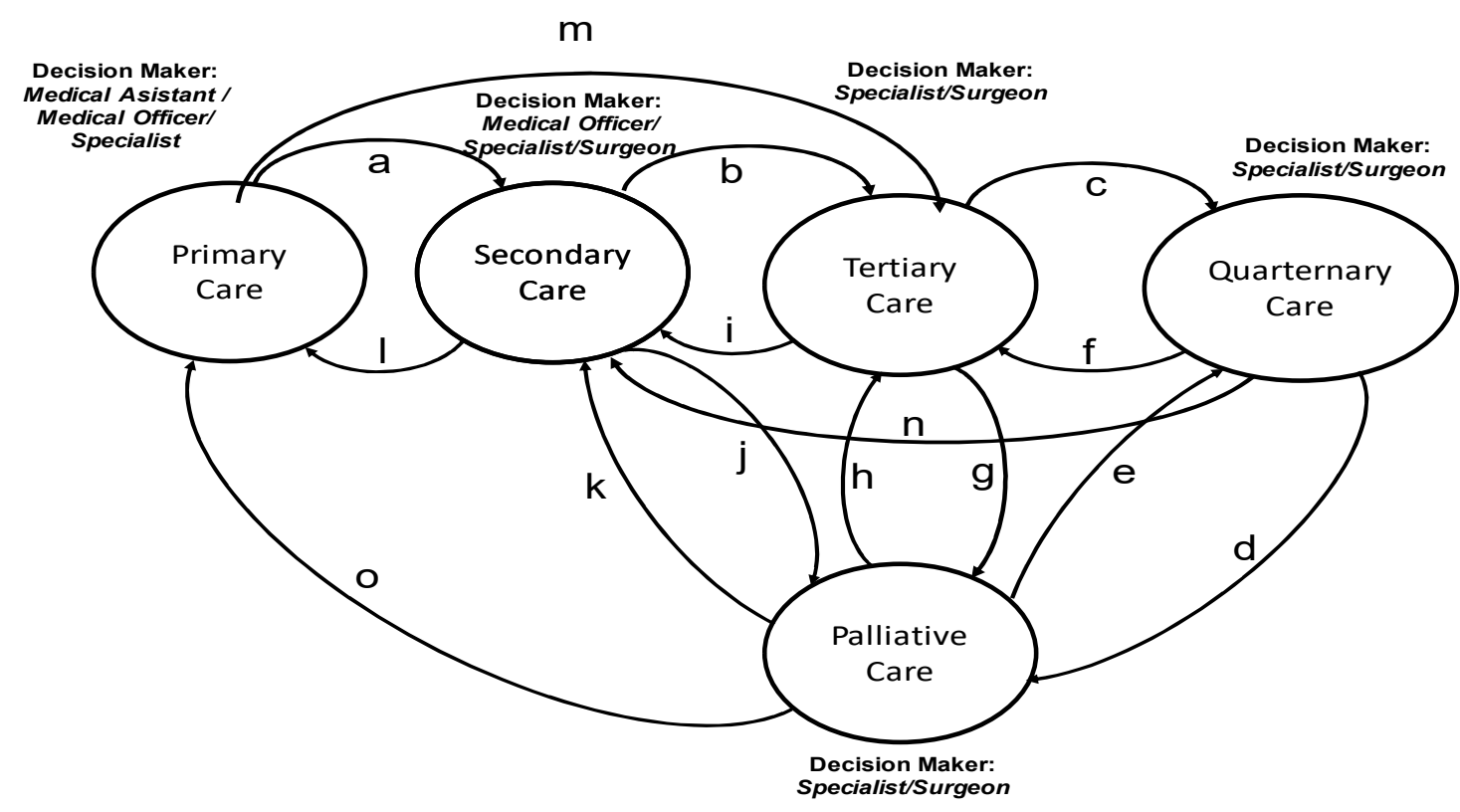

Fig.5.CARE concept for MAS based IDSS Framework development in healthcare

\section{AN ARCHITECTURE OF MULTIAGENT SYSTEM FOR HEALTHCARE IDSS}

As a result of the interview and discussion with healthcare practitioners and literature review, we found a multiagent system (MAS) for healthcare intelligent decision support system (IDSS) is suitable as a complete solution in this research. A MAS in healthcare IDSS could allow the 
medical experts to look and investigate in the whole context ofhealthcare. Therefore, here, Fig.6 presented an architecture of MAS in healthcare IDSS. Here, each intelligent agent represents each stage of the healthcare delivery services.

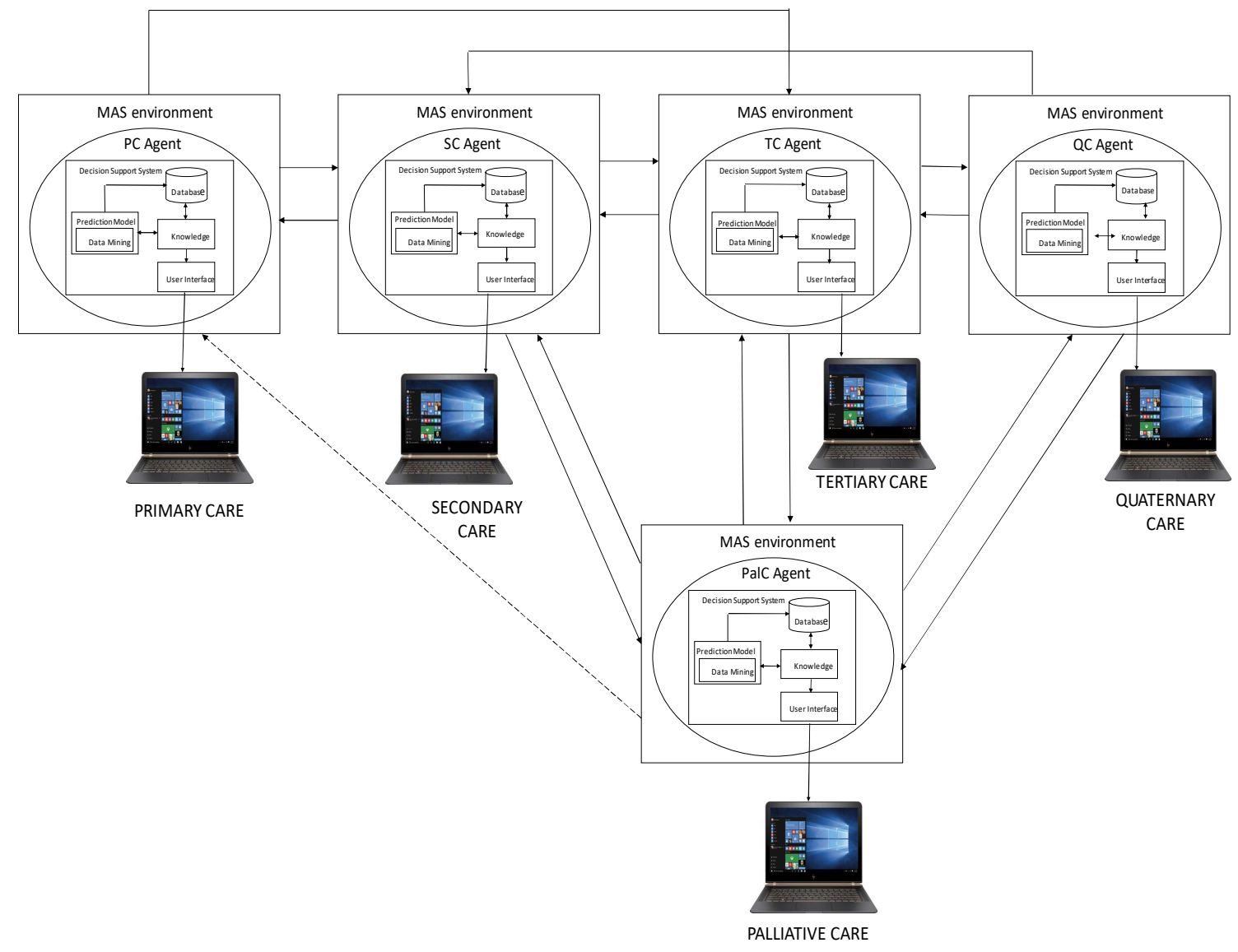

Fig.6.An architecture of MAS for healthcare IDSS

Based on Fig. 6, PC Agent represent a primary care agent, SC Agent represent a secondary care agent, TC Agent represent a tertiary care agent, QC Agent represent a quaternary care agent and PalC Agent represent a palliative care agent. Each agent will have their own database and prediction model. Any changes happen in any databases in each agent will also make every databases updated with the current changes. This will ensure each database in each agent is up to date. Hence, the prediction model will use the best data mining technique to mine the data in the database. Later, the prediction model will generate the diagnosis and suggested treatment for a particular patient requested by the user. The diagnosis and suggested treatment generated by a particular agent will be confirmed first by the decision maker in the particular agent. Then, once the confirmation has been done, a decision will be generated and 
will be submitted to the next agent which is the next stage to be submitted by the decision maker.

\section{CONCLUSION}

A MAS for healthcare IDSS that applied the CARE concept will allow the data to be always up to date in every stage of healthcare delivery services. Therefore, this situation will improve the quality and the accuracy of healthcare decision making. After this, we will develop the MAS healthcare IDSS and present in front of a group of medical experts for validation.

\section{ACKNOWLEDGEMENTS}

A special thanks to Dr. KhairuddinDato' Malek, Medical Officer at PoliklinikTaqwa, Ampang, Ipoh, Perak and Dr. NurulFarhanaZakaria, Medical Officer at UniversitiKebangsaan Malaysia Hospital,Cheras, Selangor on information and verification of information in medical field. Hence, a special thanks also to Dr. NurArzuar Abdul Rahim, Dr. Siti Noor FazliahMohd Noor, Dr. Tan KokLeng, Dr. Wong MungSeong, Dr. Noor Khairiah Abdul Karim, Dr. HasmahHussin, Dr. SitiSalmahNoordin, Dr. SharifahAzdiana Tuan Din and Dr. Hafizuddin Mohamed Fauzi, the medical specialists from AMDI, UniversitiSains Malaysia, Kepala Batas, Penang on the validation of the CARE concept.

\section{REFERENCES}

[1] Iadanza E, Guidi G, Luschi A. Chapter 7: Decision support systems in healthcare. In R. Miniati, E. Iadanza, \&F. Dori (Eds.), Clinical engineering: From devices to systems.California: Academic Press, 2016, pp. 75-93

[2] Kovačić L.,Zaletel K. L. Management in health care practice: A handbook for teachers, researchers and health professionals. Lage: Hans Jacobs Publishing Company, 2008

[3] Barton P. L.Understanding the U.S. health services system. Illinois: Health Administration Press, 2010 
[4] Taylor R. J., McAvoy B. R., O'Dowd T. General practice medicine: An illustrated colour text. London: Churchill Livingstone, 2003

[5] Kuehlein T, Sghedoni D, Visentin G. Quaternary prevention: A task of the general practitioner.Primary Care, 2010, 10(18):350-354

[6] Buckley J.Palliative care: An integrated. Chichester: John Wiley and Sons, 2008

[7] Porter M. E., Teisberg E. O. Redefining healthcare: Creating value-based competition on results.Massachusetts: Harvard Business Press.2006

[8] Levenson S A. The healthcare decision-making process framework.Maryland Medicine, 2010, 11(1):7-13

[9] Tomaszewski W. Computer-based medical decision support system based on guidelines, clinical pathways and decision nodes. Acta of Bioengineering and Biomechanics, 2012, 14(1):107-116

[10]Brahnam S, Jain L C. Chapter 1: Intelligent decision support systems in healthcare. In S. Brahnam, \&L. C. Jain (Eds.), Advanced computational intelligence paradigms in healthcare, Heidelberg: Springer Berlin, 2011, pp. 3-10

[11]OteroJ. G. C.Multi-agent systems in healthcare and bioinformatics.2010, http://www.esei.uvigo.es/fileadmin/docs/estudiantes/Traballos_fin_de_carreira/TFM_SSIA_2 009-10/Multi-Agent_Systems_in_Health_Care_and_Bioinformatics.pdf.

[12]Shaksuki E, Reid M. Multi-agent system applications in healthcare: Current technology and future roadmap. Procedia Computer Science, 2015, 52:252-261

[13]Kazar O,Sahnoun Z, Frecon L. Multi-agents system for medical diagnosis.In International Conference on Intelligent System and Knowledge Engineering, 2013, pp. 1-8

[14]Wimmer H, Yoon V Y, Sugumaran V. A multi-agent system to support evidence based medicine and clinical decision making via data sharing and data privacy. Decision Support Systems, 2016, 88:51-66

[15]Abdullah AL, Albeladi K S, AlCattan R F. Clinical decision support system in healthcare industry success and risk factors. International Journal of Computer Trends and Technology, 2014, 11(4):188-192

[16]Sukums F, Mensah N, Awine T, Meid A, Williams J, Akweongo P, Kaltschmidt J, Haefeli 
W E, Blank A. Promising adoption of an electronic clinical decision support system for antenatal and intrapartum care in rural primary healthcare facilities in sub-Saharan Africa: The QUALMAT experience. International Journal of Medical Informatics,2015, 84(9): 647-657

[17]Sukkird V, Shirahada K. Technology challenges to healthcare service innovation in aging Asia: Case of value co-creation in emergency medical support system. Technology in Society,2015, 43:122-128

[18]Hines L E, Saverno K R, Warholak T L, Taylor A, Grizzle A J, Murphy J E, Malone D C. Pharmacists' awareness of clinical decision support in pharmacy information systems: An exploratory evaluation.Research in Social and Administrative Pharmacy, 2011, 7(4):359-368

[19] Lambin P, Zindler J, Vanneste B,Voorde L V D, Eekers D, Compter I, Panth K, Peerlings J, Larue R, Deist T, Jochems A, Lustberg T, Soest J. V, Jong ED, Even A, Reymen B, Rekers N, Gisbergen M V, Roelofs E, Carvalho S, Leijenaar R, Zegers C, Jacobs M, Timmeren J V, Brouwers P, Lal J, Dubois L, Yaromina A, Limbergen E J. V, Berbee M, Elmpt W V, Oberije C, Ramaekers B, Dekker A, Boersma L, Hoebers F, Smits K, Berlanga A, Walsh S. Decision support systems for personalized and participative radiation oncology. Advanced Drug Delivery Reviews, 2017,109:131-53.

[20]Kilsdonk E, Peute L W, Riezebos R J,Kremer L C, Jaspers M W M. Uncovering healthcare practitioners' information processing using the think-aloud method: From paper-based guideline to clinical decision support system. International Journal of Medical Informatics,2015, 86:10-19

[21]Valkenhoef G V, Tervonen T, Zwinkels T, Brock B D, Hillege H. ADDIS: A decision support system for evidence-based medicine. Journal of Decision Support Systems, 2013, 55(2):459-475

[22]Han J., Kamber M., Pei J. Data mining: Concepts and techniques.California: Morgan Kaufmann Publishers, 2012

[23]Dios M, Molina P J M, Fernandez V V, Andrade P J L, Framinan J M. A decision support system for operating room scheduling. Computers and Industrial Engineering, 2015, 88:430-443 
[24]Rodriguez L S, Aziz A, Chatwin C. A service oriented approach for guidelines-based clinical decision support using BPMN. Journal of Studies in Health Technology and Informatics, 2014, 205:43-47

[25]Zhuang Z Y, Wilkin C L,Ceglowski A. A framework for an intelligent decision support system: A case in pathology test ordering. Journal of Decision Support Systems, 2013, 55(2):476-487

[26]Anooj P K. Clinical decision support system: Risk level prediction of heart disease using weighted fuzzy rules.Journal of King Saud University-Computer and Information Sciences, 2012, 24(1):27-40

[27]Casado L C, Rodríguez G A, Álvarez R J M, Colomo P R. PsyDis: Towards a diagnosis support system for psychological disorders. Journal of Expert System with Applications, 2012, 39(13):11391-11403

[28]Kim K Y, Kim Y S, Schmeler M R. Remote decision support for wheeled mobility and seating devices. Journal of Expert System with Applications, 2012, 39(8):7345-7354

[29]Park S G, Lee S, Kim M K, Kim H G. Shared decision support system on dental restoration. Journal of Expert System with Applications, 2012, 39 (14):11775-11781

[30]Riaño D, Real F, López V J A, Campana F, Ercolani S, Mecocci P, Annicchiarico R, Caltagirone C. An ontology-based personalization of health-care knowledge to support clinical decisions for chronically ill patients. Journal of Biomedical Informatics, 2012, 45(3):429-446

[31]Salmeron J L, Papageorgiou E I. A fuzzy grey cognitive maps-based decision support system for radiotherapy treatment planning. Journal of Knowledge-Based System, 2012, 30:151-160

[32]Kong G, Xu D, Body R, Yang J, Mackway J K, Carley S. A belief rule-based decision support system for clinical risk assessment of cardiac chest pain. European Journal of Operational Research, 2012, 219(3):564-573

[33]Chen Y, Hsu C, Liu L, Yang S. Expert systems with applications constructing a nutrition diagnosis expert system. Journal of Expert Systems with Applications, 2012, 39(2):2132-2156 [34]Charbonnier S, Zoubek L, Lesecq S, Chapotot F. Self-evaluated automatic classifier as a 
decision-support tool for sleep/wake staging. Journal of Computers in Biology and Medicine, 2011, 41(6): 380-389

[35]Esposito M, Pietro G D. An ontology-based fuzzy decision support system for multiple sclerosis. Journal of Engineering Applications of Artificial Intelligence, 2011, 24(8):1340-1354

[36]Lee M T, Su Z Y, Hou Y H, Liao H C, Lian J D. A decision support system for diagnosis related groups coding. Journal of Expert System with Applications, 2011, 38(4):3626-3631

[37] Sokolova M V, Fernández C A. Hybrid models in agent-based environmental decision support. Journal of Applied Soft Computing, 2011, 11(8):5243-5258

[38] Suhasini A, Palanivel S, Ramalingam V. Multimodel decision support system for psychiatry problem. Journal of Expert System with Applications, 2011, 38(5):4990-4997

[39]Uzoka F M E, Osuji J, Obot O. Clinical decision support system (DSS) in the diagnosis of malaria: A case comparison of two soft computing methodologies. Journal of Expert System with Applications, 2011, 38(3):1537-1553

[40]González V H, Mier M, Julià S M, Arvanitis T N, García G J M, Robles M, Lewis P H, Dasmahapatra S, Dupplaw D, Peet A, Arús C, Celda B, Huffel S V, Lluch A M. HealthAgents: Distributed multi-agent brain tumor diagnosis and prognosis. Applied Intelligence Journal, 2009, 30(3):191-202

[41]Su C J, Wu C Y. JADE implemented mobile multi-agent based, distributed information platform for pervasive healthcare monitoring. Applied Soft Computing, 2011, 11(1):315-325

[42]Kim H K. Convergence agent model for developing u-healthcare systems. Journal of Future Generation Computer Systems, 2014, 35:39-48

[43] Othman S B, Zgaya H, Hammadi S, Quilliot A, Martinot A, Renard J M. Agents endowed with uncertainty management behaviors to solve a multiskill healthcare task scheduling. Journal of Biomedical Informatics, 2016, 64:25-43

[44] Cruz C R, Vieira M P, Costa P, Ferreira A, Oliveira P E, Araújo F, Costa P A. Integration of hospital data using agent technologies-A case study. Journal of AI Communications, 2005, 18(3):191-200

[45]Tentori M, Favela J, Icese C, Rodríguez M D. Privacy-aware autonomous agents for 
pervasive healthcare. Journal of Intelligent System, 2006, 21(6):55-62

[46]Moghaddam M K, Shojafar M, Nami M R, Rashidi H. An efficient multi-agent system for e-health functionalities. International Journal of Software Engineering and Its Applications, 2013, 7(3):23-34

[47] Arsene O, Dumitrache I, Mihu I. Expert system for medicine diagnosis using software agents. Expert Systems with Applications, 2015, 42(4):1825-1834

\section{How to cite this article:}

Mahiddin N, Othman Z A, Baka A A. An architecture of multiagent system (mas) for healthcare intelligent decision support system (idss). J. Fundam. Appl. Sci., 2017, 9(5S), 144-167. 